Running head: HEALTH COMMUNICATION AND HEALTH EDUCATION

\title{
Health Communication and Health Education: \\ Empowering Students to Educate Their Communities
}

\author{
Jennifer J. Bute \\ Char L. Kopchick \\ Ohio University
}

[This is an Accepted Manuscript of an article published by Taylor \& Francis Group in Communication Teacher on April 15, 2009, available online:

http://dx.doi.org/10.1080/17404620902780221]

Courses: Health Communication; Gender and Health Communication; Senior Capstone Objectives

After completing this project, students will be able to: (a) use health communication research and theory to create educational materials; (b) analyze an audience and develop creative educational materials based on audience characteristics; (c) consult with key constituents during the development of educational materials.

\section{Rationale}

As Whitfield and Conis (2006) have noted, professors of communication are increasingly challenged to seek ways of integrating learning and doing in the classroom to enhance student outcomes. Service-learning projects, designed to allow students to make a substantive contribution to their campus and community, are particularly useful in providing communication students the opportunity to apply course concepts in experiential contexts (Tolman, 2005). Such 
projects simultaneously encourage the integration of theory and practice and are associated with numerous student benefits, including clarifying vocational goals, making potential career connections, gaining a sense of social responsibility, and developing regard for cultural differences (Oster-Aaland, Sellnow, Nelson, \& Pearson, 2004). Moreover, service-learning projects allow students to hone a whole host of specific communication skills, ranging from written communication to small group interactions to media literacy (Oster-Aaland et al., 2004).

This assignment asks students studying health communication to use their knowledge of health communication theory and research in the creation of educational materials to be shared with their campus or local community. Over the course of the entire term, students work in small groups to develop exhibits on important health topics (e.g., patient-provider communication, media portrayals of health issues) suitable for display in a wellness fair setting. This empowers students to serve their peers and the local community through education about important health topics. In addition to allowing students to connect theory and practice, this project provides instructors with distinctive ways to assess student knowledge and fosters a heightened sense of responsibility by holding students accountable to multiple stakeholders.

\section{The Activity}

The educational display assignment is suitable as a final project for a course on health communication. Throughout the term, students complete a series of assignments, culminating in the creation of a wellness fair display. The project affords a chance for instructors and students to collaborate with campus health centers, offices of health promotion, and community health officials in either contributing to an already existing fair (e.g., our students created exhibits for an annual health and wellness fair on our campus) or by sponsoring a new fair. 
Near the beginning of the term, students study theories of health behavior change and health promotion (e.g., Prochaska, DiClemente, and Norcross’ (1992) work on stages of behavior change), in conjunction with other course topics, to develop a theoretical foundation to inform their final projects. Next, students are assigned to groups based on shared interests, special skills and knowledge (e.g., graphic design), and other relevant criteria. Students then work cooperatively to select a health-related topic for their display that incorporates an emphasis on communication. Thus, students study not only a specific health topic (e.g., sexually-transmitted infections), they also engage in focused study of communication issues related to that health topic (e.g., safer sex negotiation). In this way, students learn about health communication on a variety of levels (see du Pre, 2005); the educational display in and of itself is a form of health communication, and each display incorporates a special emphasis on some aspect of communication (e.g., media effects, patient-provider interactions).

After selecting a topic, each group completes two short written assignments. The first is a consultation report that requires students to confer with campus or community experts (e.g., the campus director of health promotion) and write a brief report that includes an analysis of how the information gleaned in the meeting will inform the final project. For the next assignment, the groups analyze their intended audience (e.g., college students, community members) by either (a) conducting focus group sessions or (b) distributing surveys. Each group prepares a short report that summarizes their findings and includes a detailed discussion of how their findings will guide the development of their display.

On the day of the fair, students present their prepared exhibits, which can incorporate a wide range of materials and activities, such as tri-fold displays, flyers, pamphlets, games, and various give-aways. Students can be asked to contribute $\$ 10$ to the purchase of materials and 
supplies for the fair (e.g., photocopying). Students should be prepared to staff their booths on the day of the fair so that they can engage with fair attendees and answer questions about their topics. In addition to the exhibit itself, students also turn in a written report summarizing the ways in which the display meets the following criteria:

- Knowledge -does the display demonstrate a thorough knowledge of the topic? Are students able to answer questions from fair participants about their topic?

- Relevance-is the display relevant to health communication? Is the display informed by research and theory on health communication?

- Audience adaptation and engagement- is the display geared toward the primary audience? In what ways does the display encourage involvement from fair attendees?

- Creativity-is the display unique? Does the display draw attention?

- Professionalism-is the appearance of the display neat? Are written materials free from typos and grammatical errors?

These five criteria can also be used as instructors assign final grades for the project. By assessing knowledge, relevance, audience adaptation and engagement, creativity, and professionalism, instructors can evaluate whether students have met the three objectives for the project. For instance, assessing knowledge and relevance allows instructors to evaluate the extent to which students used health communication research and theory accurately and effectively in creation of their educational materials. Instructors can also evaluate how students incorporated the results of their audience analysis assignment in their fair displays (e.g., did they address issues or questions raised by their sample?). Finally, the level of creativity and professionalism evident in their displays is one way of measuring how successfully they consulted with key constituents (in our case the staff who planned the campus-wide fair). 
The assessment criteria also highlight the unique features of this project. In assessing students' knowledge of the topic, instructors do not have to rely solely on the display and written report. They can also observe students as they interact with fair participants and consider whether students are able to answer questions adequately. In fact, we found that participants asked challenging questions of our students that we ourselves had not considered. The criteria for evaluation, especially the emphasis on audience analysis, also demonstrate that students are accountable to a variety of stakeholders (not just themselves and their instructors), including fair participants and event organizers. After the fair, students write short individual reflection essays in which they analyze their experience. For instance, students write about what they learned from their participation in the fair and discuss how the fair and their involvement benefited the campus community. Such structured reflection is a key component of service-learning assignments (Dubinsky, 2006).

Throughout the term, instructors can use this project as an impetus for addressing social justice and confronting issues of power and privilege. In our case, we based our understanding of health communication on the notion that health and illness are socially constructed (Lorber \& Moore, 2002). In doing so, we encouraged students to include an activism component in their educational displays by raising consciousness about critical health issues and encouraging fair participants to take action. We also urged students to consider how the social construction of health affects access to health care and other health resources (e.g., affordable medications, credible health information).

\section{Debriefing/Results}

Students in our course developed displays for a campus-wide health and wellness fair and served their peers by providing vital information on health topics relevant to a college student 
population. Allowing students to select their own topics and develop them over the course of the term gives students the freedom to conduct an in-depth exploration of a topic about which they are passionate. Our students educated fair attendees about a wide range of issues. One group created an exhibit on the ways that peer communication and media images can influence body image and self-esteem for college-aged women. They incorporated a television and DVD player in their display and showed clips from popular television shows and movies so that they could discuss the effects of these images with fair participants. Another group focused on safer sex negotiation in their exhibit and shared information on the various verbal and nonverbal strategies partners use to communicate their desire to engage in safer sex practices. They also created an interactive game in which fair attendees answered questions about how they might handle difficult negotiation conversations. A third group chose to educate college women about the importance of the Gardasil vaccine for prevention of human papillomavirus (HPV). Their poster included a flow chart explaining how to access the vaccine and explicitly addressed communication issues, such as questions to ask health care providers regarding risks and benefits of the vaccine and questions to ask health insurance companies about coverage for the vaccine. The Gardasil group offers a prime example of how students addressed issues of power and privilege in their displays. By providing participants with information on talking to health care providers, the students acknowledged that patient-provider interactions are imbued with paternalistic undertones and sought to empower participants with tools to communicate their needs and concerns. The students also recognized that some fair participants do not have access to insurance coverage and included information on acquiring the vaccine for free or at a reduced cost. 
Students' reflection essays demonstrated that they benefited from the project in many of the ways suggested by Oster-Aaland and colleagues (2004). For instance, a student from the media and body image group wrote, “One experience that I will walk away from this class remembering is the health and wellness fair...I always knew the media had a strong influence on young girls, but I would never have guessed how extensive it is!” Another commented that her interactions with fair participants solidified her commitment to pursue a career in health education, and yet another student learned through the project "that a graduate degree in public health or health communication would open up career opportunities.” Finally, a number of students commented that they enjoyed the opportunity to develop a final project with such a tangible and beneficial outcome.

\section{Appraisal and Variations}

This project sought to couple learning with doing and to integrate communication theory and practice. By using their creativity to develop educational materials on topics related to health communication, students applied theoretical knowledge gained through classroom lecture, group research, and course readings in an experiential context. They also had an opportunity to serve their campus by teaching their peers about critical and relevant health issues.

This assignment can be modified in various ways to meet the needs of individual instructors and communities. Some instructors might be reluctant to use group projects as a significant portion of the final grade in the course. In these situations, instructors could change the assignment to allow students to work individually or could include a significant number of individual assignments to balance the weight of a group project when calculating final grades. In our case, we used various mechanisms to prevent the problems that can plague group projects. We dedicated a portion of class time each week to in-class group meetings. This allowed us to 
monitor group progress and resolve conflicts as they arose. We also helped to ensure individual accountability in the groups by assigning a peer evaluation measure so that students could assess the extent to which their fellow group members contributed to the final project. Finally, making several assignments due prior to the fair guaranteed that each group was working toward the goal of creating a useful and well-researched exhibit.

On campuses that do not sponsor an annual health and wellness fair, instructors could consider several alternatives. Working with community officials in local health agencies (e.g., county health departments) is one option that would allow students to extend the reach of their materials to the community at large. Alternatively, instructors and students could collaborate with other campus departments (e.g., health and human services) to sponsor their own mini-fair on campus. A single class could even host a small scale event in which students invite friends, classmates, and faculty members to attend a fair held during the class's regular meeting time. Particularly ambitious instructors could work with their students to start a health and wellness fair on their campus or in their local community with the potential for that fair to become an annual event. As instructors pursue variations on this assignment, they will no doubt encounter new challenges related to power and privilege. In our case, students addressed an audience of health fair participants who were similar to them in many ways (e.g., most fair participants were also college students with access to care at a campus health center). However, if students enter their local communities, they might encounter new challenges as they interact with participants of various backgrounds (e.g., varying education levels, diverse socioeconomic backgrounds) who might lack access to adequate health care and resources. Whatever path instructors pursue, students will be given a unique opportunity to put research into practice as they serve the larger campus or local communities in which they live. 
References and Suggested Readings

du Pre, A. (2005). Communicating about health: Current issues and perspectives. Mountain View, CA: Mayfield.

Dubinsky, J. (2006). The role of reflection in service learning. Business Communication Quarterly, 69, 306-311.

Lorber, J., \& Moore, L. J. (2002). Gender and the social construction of illness. Lanham, MD: Alta Mira.

Oster-Aaland, L. K., Sellnow, T. L., Nelson, P. E., \& Pearson, J. C. (2004). The status of service learning in departments of communication: A follow-up study. Communication Education, 53, 348-356.

Prochaska, J. O., DiClemente, C. C., \& Norcross, J. C. (1992). In search of how people change. American Psychologist, 47, 1102-1114.

Tolman, E. G. (2005). Service-learning in the interpersonal communication course: Using field notes and storytelling. Texas Speech Communication Journal, 30, 92-97.

Whitfield, T. S., \& Conis, A. D. (2006). War veterans' memoirs as narrated to students: An intergenerational service-leaning project for interpersonal communication. Communication Teacher, 20, 23-27. 